\title{
Arbor
}

\section{La Justicia como valor Constitucional}

\section{Landelino Lavilla Alsina}

Arbor CLXXV, 691 (Julio 2003), 1043-1057 pp.

La Constitución Española, sin menoscabo de su carácter prescriptivo, atiende a la necesidad de poner un vigoroso acento -y mejor si lo hace en términos jurídicos-sobre las notas identificadoras del aliento politico que más y mejor expresan el fundamento y orientación de la voluntad constituyente. Pero, con independencia de tal aseveración, es definitiva la interpretación del precepto, según criterios y métodos jurídicos, en cuanto enuncia unos «valores» que el Estado constituido «propugna», que se califican como «superiores»y que se predican, precisamente, del «ordenamiento jurídico».

La justicia es, desde luego y en sí misma, un valor, al que conviene la nota de clásico en la determinación de los que han de regir una convivencia política estable. Uno u otro sentido de la justicia ha latido con fuerza en la conciencia humana y en toda pretensión racional de ordenación de la convivencia.

1. El Estado social y democrático de Derecho, en que España se constituye, "propugna como valores superiores de su ordenamiento jurídico la libertad, la justicia, la igualdad y el pluralismo político».

El sentido de la acción verbal («propugna») y la precisa indicación de la libertad, la justicia, la igualdad y el pluralismo político como «valores» parecen más propios de una declaración programática que de una disposición normativa. No es, por ello, extraño que en los preám- 
bulos de diversas Constituciones puedan hallarse, con análoga significación, proclamaciones de objetivos que fundan y comprometen la voluntad política constituyente. No es, sin embargo, usual que una tal proclamación se incorpore, con patente intención prescriptiva, al texto de la norma.

Es más, en el propia Preámbulo de la Constitución española de 1978, cuyo artículo 1.1 contiene aquella prescripción, puede leerse que la Nación española se siente eficientemente impulsada por el deseo de «establecer la justicia, la libertad y la seguridad» y de «promover el bien de cuantos la integran».

En ningún caso cabe inferir, sin embargo, la existencia de previsiones constitucionales prescriptivas en contraposición a previsiones constitucionales programáticas. En todas ellas hay sustancia normativa propia, aunque difieran los sujetos llamados primariamente a su cumplimiento y aunque varíen los márgenes de opción constitucionalmente deferidos al legislador.

La Constitución es, pues, una norma y en todas sus disposiciones luce su sustancia normativa. ¿También en el artículo 1.1 al enunciar los valores superiores del ordenamiento jurídico propugnados por el Estado social y democrático de Derecho?. También, desde luego, con el sentido y alcance que son propios de su configuración constitucional.

2. La esencia normativa del artículo 1.1 radica en la cabal manifestación de la voluntad constituyente: «España se constituye en un Estado social y democrático de Derecho». Pero, si se limitara la consideración del artículo 1.1 al párrafo transcrito, es claro que se produciría una fragmentación, no arbitraria pero sí amputadora, de lo que el artículo 1.1 dice. Porque a aquella oración principal acompaña otra subordinada (como hace visible el pronombre relativo «que»), a cuyo tenor el Estado social y democrático de Derecho «propugna como valores superiores de su ordenamiento jurídico la libertad, la justicia, la igualdad y el pluralismo político». La cuestión está ahora en dilucidar si esta oración subordinada es, en sí misma, una mera especificación indicativa o participa de la decisión constitutiva que formula la oración principal.

Si el artículo 1.1 es normativo, en cuanto expresión con plena eficacia jurídica de la voluntad constituyente («España se constituye»), la determinación de «en qué se constituye», como complemento circunstancial de la oración, fija el objeto de la acción verbal («se constituye»), de suerte que el definido como Estado social y democrático de Derecho se inserta, de modo natural y con fuerza imperativa, en el contenido nuclear de la norma. 


\section{La Justicia como valor Constitucional}

La manifestación subsiguiente (oración subordinada), según la cual el Estado social y democrático en que España se constituye «propugna como valores superiores de su ordenamiento jurídico la libertad, la justicia, la igualdad y el pluralismo político», podrá ser objeto de enjuiciamiento crítico acerca de la necesidad, la conveniencia o el acierto (sea por su contenido, sea por su forma gramatical) de su inserción en el precepto del artículo 1.1. Cabrá subrayar, desde este punto de vista, que cierto sentido, propio de una especificación explicativa, permite cuestionar la corrección técnica de adosarla a la autosuficiente e inicial declaración dispositiva «España se constituye en un Estado social y democrático de Derecho».

Las objeciones al artículo 1.1 son comprensibles si se cuestiona la superposición y hasta duplicación de sus respectivos ámbitos de cobertura. Pero hay que rendir tributo a la expresividad jurídico-política de la dicción constitucional - frente a excesos conceptuales rigoristas-.

El artículo 1.1 es, pues, claramente normativo, en todo su contenido, como manifestación de la voluntad constituyente. Ésta identifica un Estado de Derecho (apelación a una categoría dogmática vigente en la doctrina y en la realidad) que queda explícitamente cualificado, además, por ser social, por ser democrático y por propugnar la libertad, la justicia, la igualdad y el pluralismo político.

La norma constitucional atiende así, también, a la necesidad de poner un vigoroso acento -y mejor si lo hace en términos jurídicossobre las notas del aliento político que más y mejor expresan el fundamento y orientación del acto constituyente. Pero, con independencia de tal aseveración, es definitiva la interpretación del precepto, según criterios y métodos jurídicos, en cuanto enuncia unos «valores» que el Estado constituido «propugna», que se califican como «superiores» y que se predican, precisamente, del «ordenamiento jurídico».

Sea una u otra la concepción filosófica que se profese, difícilmente puede negarse que sean propiamente «valores» los que como tales aparecen enunciados en el artículo 1.1. Ni siquiera desde posiciones inspiradas en un Valor absoluto o residenciado en el plano de lo trascendente se niega la existencia de un conjunto de valores, cuya significación inmanente y relativa, al punto de ser variables en sí mismos y en su jerarquización, en nada desvirtúa, al menos como simple dato empíricamente comprobado, su existencia y aprecio en cuanto tales valores. Y, sobre el presupuesto de que la voluntad constituyente se traduce en un Estado expresamente caracterizado como «social y democrático de Derecho», luce sin reservas la coherencia de 


\section{Landelino Lavilla Alsina}

que ese Estado propugne, como valores, la libertad, la justicia, la igualdad y el pluralismo político.

Esa coherencia se advierte sin más que percibir el engarce entre aquella caracterización del Estado constituido y los valores enunciados. $\mathrm{Y}$, naturalmente, esa percepción resulta manifiesta, aun haciendo abstracción del juicio que pueda merecer la selección de valores hecha y su calificación como «superiores» respecto de otros valores, no menos coherentes, pero no incluidos explícitamente en el artículo 1.1. Así, por ejemplo, la seguridad que, en paridad conceptual con la libertad, aparece invocada en el preámbulo y no se enuncia en el artículo 1.1, aunque -al igual que otros e incluso los relacionados - sea inferible de la identidad de un Estado social y democrático de Derecho y conste en el despliegue del texto constitucional.

Lo que importa, pues, es dejar ya establecido que la libertad, la justicia, la igualdad y el pluralismo político expresan valores y que, además, con toda propiedad pueden y deben entenderse asociados a la realidad querida y proclamada de un Estado social y democrático de Derecho. Cuestión distinta es si el artículo 1.1 ha sido certero en su selección de valores jerarquizados como «superiores». También distinta es la cuestión, consiguiente al juicio que merezca aquel criterio selectivo, de si los valores enunciados muestran su verdadera entidad en la determinación individualizada de cada uno o identifican una realidad unitaria en la que todos convergen y cada uno adquiere pleno sentido o, por el contrario, se producen interferencias y superposiciones entre ellos que hacen discutible la misma relación de valores seleccionados.

3. La justicia es, desde luego y en sí misma, un valor, al que conviene la nota de clásico en la determinación de los que han de regir una convivencia política estable; es un dictado de la más noble condición humana, un legado histórico que marca la orientación del Derecho y que está arraigado en la propia convicción social generalizada. Sin pretensión alguna de introducir una ordenación axiológica, en la justicia se acusan, con exigencias más intensas y con mayor alcance en su proyección de cobertura, los perfiles nítidos de un auténtico valor. En el pensamiento jurídico y político, con dispares reflejos en la realidad, se hallan sutiles y profundas reflexiones acerca de la justicia, que se han traducido en consecuencias analíticas diferenciadoras de sus especies (conmutativa, distributiva, general, social); pero uno u otro sentido de la justicia ha latido con fuerza en la conciencia humana y en toda pretensión racional de ordenación de la convivencia. 


\section{La Justicia como valor Constitucional}

El que es jurista es custodio de la justicia y el que no es eso no es nada», según la expresión tantas veces recordada de San Agustín. Cicerón tradujo su brillante experiencia forense y política encareciendo la necesidad personal y social de las cuatro virtudes cardinales que habían ya identificado los filósofos estoicos: la prudentia o perspicacia, la justitia, que es precisamente la virtud más propia del jurista, la temperantia o moderación y la fuerza o fortitudo.

El recto o interesado entendimiento de la justicia ha suscitado controversias sin fin y aún hoy alimenta afanes disquisitivos e inagotables pretensiones definitorias. Pero es lo cierto que ni las móviles fronteras entre lo justo y lo injusto han logrado poner en pie y sostener una verdadera tensión entre defensores de la justicia y defensores de la injusticia. La polémica conceptual se ha desenvuelto en el seno de la justicia (determinación de qué es lo justo) y no respecto de la injusticia como tal. Incluso algunas ideas - como la de Goethe, al mostrar su preferencia por la injusticia con orden frente a la justicia con desordentuvieron fortuna en su circulación por la feliz expresión literaria y por su fondo paradójico capaz de aguijonear una realidad transida de contradicciones. No, en cambio, por articular una dialéctica entre justicia $\mathrm{y}$ orden que no fuera reductible a la denuncia de que en el desorden puede naufragar la justicia. En cualquier caso la expresa proclamación de la justicia como valor constitucional y su afirmación como meta del ordenamiento jurídico comporta, en puridad y frente a desviadas interpretaciones (constricción del orden al «orden público» en su sentido descarnado como ausencia o represión incondicionada de conflictos), una mediación del Derecho como instancia ordenadora de la convivencia $\mathrm{y}$ en la que se asienta la justicia como valor superior.

Aunque este último dato fija, en términos paralelos, la significación de la libertad, la igualdad y el pluralismo político en la Constitución española, es patente que su proclamación como valores superiores del ordenamiento jurídico se alcanza - a diferencia de lo que ocurre con la justicia - tras un proceso en el que se imponen a través de ciertas tensiones dialécticas -en el pensamiento, en la política y en el propio Derecho- con sus antitéticos: la servidumbre, la desigualdad, el monolitismo político.

En cualquier caso, algunas puntualizaciones clarificadoras parecen convenientes, si no necesarias, a la vista de determinadas y quizá apresuradas interpretaciones:

a) Es claro que existen eslabones de conexión entre la proclamación de la justicia como valor superior del ordenamiento jurídico y la regulación contenida en el Título VI de la Constitución que, bajo la 
rúbrica «Del Poder Judicial», se inicia con el siguiente enunciado normativo: «la justicia emana del pueblo y se administra en nombre del Rey por Jueces y Magistrados integrantes del poder judicial, independientes, inamovibles, responsables y sometidos únicamente al imperio de la Ley» (artículo 117.1).

El reconocimiento de tales eslabones, sin embargo, no ampara un lineal y excluyente alcance de la justicia como valor circunscrito a la concepción y al desempeño de la función jurisdiccional «juzgando y haciendo ejecutar lo juzgado» (artículo 117.2). No lo ampara ni lo consiente.

La circunstancia de que el sujeto gramatical del artículo 117.1 sea «la justicia» se presta a algunas reflexiones respecto del significado que la justicia tiene en el preámbulo, en el título preliminar y en las partes dogmática y orgánica de la Constitución. Sería absurdo pretender que ninguna relación existe entre las apelaciones a la justicia en el Título VI y en los demás preceptos de la Constitución. Pero sería igualmente una simpleza afirmar la identidad de sentido y considerar que el significante «justicia» en la Constitución tiene un significado unívoco y no varios aunque ciertamente sean analógicos.

A este respecto, resulta evidente que, cuando el preámbulo invoca el deseo de establecer «la justicia» o declara la voluntad de garantizar un orden económico y social «justo» y cuando el artículado proclama «la justicia» como valor superior del ordenamiento jurídico (artículo 1.1) o se refiere a un sistema tributario «justo» (artículo 31), acogen una acepción de la justicia que no se circunscribe a la función de administrar justicia a la que, en cambio, sí se ciñen las referencias a la justicia del Título VI de la Constitución.

El énfasis que el artículo 117 de la Constitución pone en «la justicia» no puede debilitar la inmediata inteligencia de que - preservado el vigoroso y expansivo sentido de su afirmación inicial «la justicia emana del pueblo»- está en realidad concebido, según revela la fórmula verbal reflexiva "se administra», pensando en la función de «administrar justicia» mediante el ejercicio de la potestad jurisdiccional.

La construcción dogmática y la realización práctica del Estado de Derecho - y con mayor impulso expansivo si se califica como «social»han desplazado, hasta el mundo agostado de las ideas inservibles, aquellas que otrora fueron ambiciosas y fecundas en la evolución del pensamiento jurídico-político y que, situando la justicia en el ámbito propio del poder judicial y en la función tuitiva y garante de éste, entendían su proyécción, respecto de los demás poderes públicos, sólo como cauce formal y límite material de su acción. 


\section{La Justicia como valor Constitucional}

En el Estado moderno, la realización de la justicia queda propuesta, como objetivo permanente aunque sea tarea infinita, a todos los poderes públicos con las naturales variaciones —que en nada afectan a su esencia como valor - correlativas a las distintas funciones que respectivamente tienen atribuidas. Como se ha dicho en términos expresivos y por referencia a la Administración (Stael), cuando ésta asume atribuciones conformadoras del orden social la justicia no es para ella un simple límite sino que es orientación y objetivo.

La voluntad normativa expresada en el artículo 1.1 de la Constitución, con la significación propia de una disposición preliminar y erigiendo la justicia en valor superior del ordenamiento jurídico, respalda la concluyente convicción de que todo el texto constitucional - cabecera de ese ordenamiento- se halla transido por los requerimientos de la justicia, a los que necesariamente han de plegarse en su actuación todos los poderes públicos, con inclusión del poder judicial en el ejercicio de la potestad jurisdiccional y sin exclusión de ningún poder en el desempeño de sus funciones.

b) La concepción de la justicia como valor superior del ordenamiento jurídico comporta realzar su sentido objetivo, perfectamente discernible de su consideración como virtud individual o como atributo personal.

Ninguna objeción puede merecer el deseo, no meramente retórico, de que todos los españoles sean justos. Pero propugnar la justicia como valor superior del ordenamiento jurídico, aunque pueda expresar aquel deseo, halla su raíz en la aceptación realista de que el punto de partida no es el reino de la justicia sino un mundo profundamente injusto en el que adquiere plenitud de sentido la voluntad normativa de propugnar - pugnar por - la justicia.

Sin perjuicio de que el propio texto constitucional ofrezca ejemplos de análoga significación, el preámbulo acredita una singular expresividad cuando, tras anunciar el deseo de la Nación española de establecer la justicia, la libertad y la seguridad, proclama la voluntad de «garantizar la convivencia democrática dentro de la Constitución y de las leyes conforme a un orden económico y social justo». La unidad léxica sustantiva es el orden económico y social que, al ser calificado ya como justo, acuña el objetivo final -quizá inalcanzable en su plenitud- al que se dirige un Estado que, por decisión constituyente, queda vinculado a las exigencias de la justicia como valor superior del ordenamiento jurídico. La consecución de ese orden económico y social justo sería, sin duda, posible en una comunidad de hombres «justos» y el grado en que arraigue la justicia como deseo o virtud en la conciencia social, aunque sea tibio o abiertamente contradictorio 
el comportamiento de los miembros de la sociedad, se erige, también sin duda, en referencia directa para calibrar la mayor o menor asequibilidad de la meta propugnada. Pero los requerimientos de la justicia como valor del ordenamiento jurídico no están inmediatamente dirigidos a que sean «justos» los hombres que integran la Nación española sino a que sea «justo» el orden en que se realiza la convivencia política.

Esta reflexión desvela un plano en el que acusan cierta heterogeneidad los denominados valores superiores del ordenamiento jurídico. Basta considerar que la justicia, aunque puede como tal ser referida a un sujeto personal (hombre justo), se predica, en puridad, de un sujeto objetivado e impersonal (la sociedad, el Estado, el sistema de convivencia, el ordenamiento jurídico). Únicamente cabría admitir que la consideración de que son «justos» los integrantes de la sociedad en su conjunto refleja una aspiración y un deseo - metajurídicos-cuya plasmación en la realidad condiciona la expectativa de que el orden de convivencia sea justo con mayor o menor intensidad y extensión. Desde otro punto de vista, cabe entender, ciertamente, que la específica cualidad de "hombre justo» ha de radicar - y ser reconocida- en los titulares de funciones públicas $-\mathrm{y}$ en particular en aquellos a quienes se encomienda la administración de justicia, en un sentido estrictopara que el progreso hacia la realización de la justicia sea efectivo.

Con mayor claridad y sin concesión posible al subjetivismo, hay que considerar que el pluralismo político - consustancial a la cualificación democrática del Estado y del sistema de convivencia- sólo es predicable de sujetos objetivados pero no de individuos personales. Cualquier hombre con sinceras convicciones democráticas asume naturalmente el pluralismo político como valor, pero éste no es realizable en él sino en el orden social y en el Estado, al carecer de cualquier dimensión como atributo personal. Podrá decirse de un hombre que es justo, que es libre o que es igual a los demás, podrá incluso propugnarse que lo sea. No cabrá decir ni propugnar, en cambio, que un hombre sea políticamente plural, aunque pueda abrazar el pluralismo como valor de la convivencia y traducirlo en comportamientos de respeto y tolerancia democráticamente virtuosos.

La libertad y la igualdad, por el contrario, proyectan sus requerimientos en una doble dirección en cuanto son atributos personales (hombres libres e iguales) y en cuanto son predicables del sistema de convivencia. Una y otra dimensión no son en sí mismas divergentes ni resultan fecundas más que por su armónica conciliación. No hay hombres libres e iguales en un sistema de convivencia en que la libertad esté proscrita y cualquier discriminación tenga cabida, ni es posible 


\section{La Justicia como valor Constitucional}

un sistema de convivencia, cualificado por la libertad y la igualdad, en que los hombres no sean libres e iguales. Esa convergencia radical no neutraliza la validez de la disección hecha ni aun en términos estrictamente jurídicos. En la Constitución española de 1978 lucen una y otra dimensión en el artículo 1.1 (la libertad y la igualdad como valores superiores del ordenamiento jurídico) y en el artículo 9.2 (la libertad y la igualdad como atributos personales cuya promoción corresponde a los poderes públicos para que sean reales y efectivos).

Es más, sólo a partir de la distinción analítica hecha es correctamente inteligible nuestro texto constitucional. Si se prescindiera de ella, el artículo 9.2 suscitaría perplejidad y merecería serias reservas críticas, porque ¿acaso los poderes públicos no han de promover las condiciones y remover los obstáculos para que la justicia y el pluralismo político sean reales y efectivos en el Estado social y democrático de Derecho?. La respuesta negativa a esta interrogación es, naturalmente, inadmisible.

Tras las reflexiones hechas, adoptando como punto de partida la heterogeneidad de planos en que pueden situarse y desenvolverse los valores enunciados en el artículo 1.1 de la Constitución, urge vedar un posible e inmediato desencadenamiento de objeciones críticas y hasta descalificadoras. Para ello basta con subrayar el rigor homogeneizador que preside, no ya la enunciación sucesiva de la libertad, la justicia, la igualdad y el pluralismo político, sino su precisa calificación como valores superiores del ordenamiento jurídico. En ese plano, el de los valores superiores del ordenamiento jurídico, son estrictamente homogéneos los enunciados como tales por el artículo 1.1 de la Constitución. La existencia o no de otros planos, en los que tales valores acrediten dimensiones específicas y distintas, en nada desvirtúa la homogeneidad fundamental con que se captan, primero, y se proclaman, después, como valores superiores del ordenamiento jurídico.

Ciertamente, no hay por qué cerrarse en actitud dogmática frente a eventuales posiciones que cuestionen la selección de valores que hace el artículo 1.1, su calificación como superiores y hasta la pertinencia de la concepción misma del artículo, en cuanto parece acoger la reviviscencia de ciertos posos iusnaturalistas, aunque sean inmanentes y racionalistas y aunque se traten de enmascarar con su discutible positivación en el primero de los artículos de la Constitución. Pero, en el momento actual de la argumentación, procede dejar establecidas dos aseveraciones. En primer lugar y en estricta interpretación del artículo 1.1 de la Constitución, tal como aparece formulado y con independencia de cuál hubiera podido o debido ser su contenido, los 
valores que propone tienen sustancia normativa, no sólo porque participan de la dimensión jurídica del acto constituyente al cualificar el Estado constituido, sino porque vinculan, de una parte, a los poderes públicos situados en la obligación jurídica de pugnar por ellos y marcan, de otra, la orientación a todo el ordenamiento jurídico del que se predican tales valores como superiores.

En segundo lugar, cabe ya afirmar que el sentido propio de cada uno de los valores demanda su armónica composición con los demás, implícitamente articulados en la concepción del Estado social y democrático de Derecho y expresivamente trabados en la feliz formulación del preámbulo al proclamar la voluntad de «garantizar la convivencia democrática dentro de la Constitución y de las leyes conforme a un orden económico y social justo».

c) Ha quedado afirmada la sustancia normativa propia del contenido íntegro del artículo $1.1 \mathrm{y}$ se ha venido reflexionando desde la consideración capital de la justicia como valor del ordenamiento jurídico, aunque de modo inevitable el razonamiento se haya trasvasado al ámbito propio de los otros valores, fijando - o apuntando simplementeelementos de contraste y de conexión.

Es posible - tal vez seguro- que el atento lector haya percibido en esta prioritaria atención a la justicia, no ya -0 no sólo- una manifestación de un criterio de ordenación sistemática, con sus ineludibles dosis de convencionalismo, sino una manifestación -querida o inconsciente- de una cierta preeminencia en el aprecio y en la significación de la justicia entre los valores superiores del ordenamiento jurídico. Frente a esa percepción, la renuncia a cualquier intento de ordenación axiológica pudiera no tener otra relevancia que la de una prevención cautelar y defensiva. Y, en verdad, dejando ahora al margen el pluralismo político por la singularidad de sus perfiles, es cabalmente coherente con la línea de pensamiento seguida al reconocer a favor de la justicia una entidad, como valor, más acabada y comprensiva que la correspondiente a la libertad y a la igualdad.

Desde un punto de vista dogmático - que, en nada debilita, a efectos de la interpretación constitucional y de la construcción de una teoría sobre la Constitución española, la paridad de posición jurídica en que los valores se sitúan-, es lo cierto que la libertad y la igualdad, entre las que la justicia se enuncia, tanto pueden ser consideradas como presupuestos $\mathrm{u}$ objetivos necesarios para la consecución de la justicia propugnada (líneas de dirección y promoción en la acción de los poderes públicos a fin de que la justicia se haga realidad; anhelos incapaces de discurrir por derroteros ajenos a la justicia), cuanto pueden 


\section{La Justicia como valor Constitucional}

proponerse porque son justas y, por lo mismo, indeclinablemente requeridas por los más sólidos postulados de la justicia. Y cabría añadir - sin vacilaciones por mi parte- que en la caracterizada tensión entre libertad e igualdad la síntesis fecunda se alcanza precisamente en el esplendor de la justicia.

No sería perturbador, por tanto, para mi concepción del artículo $1.1-\mathrm{y}$ sigo dejando aparte la mención del pluralismo político-, que la justicia hubiera sido proclamada como el valor superior, por antonomasia, del ordenamiento jurídico. No hay en ello deformación originada por la propia vocación o profesión. Como no hay deformación, fruto de la sensibilidad fomentada al calor de una acusada experiencia política, al reconocer, sin rebozo ni reticencia, la vigorosa fuerza expresiva de una formulación que enuncia en paridad de posición a dos valores, libertad e igualdad, que han sido fermento, para la confrontación o la concordia, de las modernas concepciones políticas del siglo XX.

Las reflexiones recién hechas pueden no merecer otra estima que la de un reconocimiento a la sinceridad que las inspiran. Cumplen, desde luego, una función explicativa de por qué estas meditaciones se han nucleado, inicialmente, en torno a la justicia, aunque no hayan faltado referencias ni hayan podido omitirse argumentaciones sustantivas respecto de los demás valores superiores del ordenamiento jurídico.

4. La eficacia normativa - y no meramente programática o declarativa- del artículo 1.1 de la Constitución aparece ratificada, si necesario fuera, por tres datos que han de ser subrayados: la utilización de la acción verbal (propugna), la calificación como superiores de los valores que enuncia y la referencia de éstos, precisamente en cuanto valores superiores, al ordenamiento jurídico.

a) Por el propio significado del verbo propugnar, siendo el sujeto de la acción verbal el Estado social y democrático constituido, es evidente que los valores incluidos en la relación del artículo 1.1 identifican, en su individualidad $\mathrm{y}$, sobre todo, en su armónica conjugación, una meta propuesta en la que, al menos como aspiración sostenida e indeclinable, sean reales la libertad, la justicia, la igualdad y el pluralismo político. Ello comporta el reconocimiento de una situación de partida distante de la plenitud de los valores propugnados. En puridad, los valores superiores tanto expresan cualificaciones queridas del orden. que se constituye cuanto acreditan un impulso dinámico en pos de preservar o conseguir su mayor efectividad. Por inmediata verificación empírica, se parte del reconocimiento de carencias e insuficiencias; por voluntad normativa se promueve una eficiente acción para superarlas y progresar en la dirección que aquellos valores señalan. 
El verbo utilizado - propugnar-, en su primaria acepción y en la evocación etimológica de la lucha (luchar por, pugnar por), sitúa al Estado constituido en posición beligerante, activa, al servicio de la efectividad de los valores propugnados. Tales valores son directa e inmediatamente inferibles de la propia cualificación del Estado (Estado social y democrático de Derecho), pero la virtualidad del artículo 1.1 no se agota en la cierta redundancia - nunca vacuidad - de su explícita consignación, sino que, por su fuerza vinculante, impone en términos jurídicos la efectiva acción de los poderes públicos dirigida hacia la consecución de aquellos valores.

b) Muchos y de distinto rango son los valores que, en abstracto, pueden detectarse o proponerse en cualquier sistema de convivencia jurídicamente ordenado; también, en concreto, en el texto constitucional que preside el ordenamiento español. La armonización de tales valores y su jerarquía requiere con frecuencia esfuerzos interpretativos de cuyo rigor y finura existen abundantes ejemplos en los repertorios jurisprudenciales de los órganos de justicia constitucional. En las sentencias del Tribunal Constitucional español, por supuesto, no falta la presencia expresa o la perceptible resonancia de la jerarquización de valores que supone la calificación normativa como «superiores» de los acogidos por el artículo 1.1.

c) Los valores superiores propugnados lo son del ordenamiento jurídico. Esa mediación del Derecho impulsado por y hacia la realización de valores, al igual que el personalismo fundamentador del orden político y de la paz social (artículo 10), ha suscitado la cuestión de si en nuestro texto constitucional hay resonancias de un iusnaturalismo, aunque sea inmanente y racionalista.

Posiciones iusnaturalistas en actitud de resistencia o de resignada languidez quisieron ver $-\mathrm{y}$ no sin fundadas razones- que algunos rescoldos se avivaban: la proclamación de la justicia como valor superior del ordenamiento jurídico y el reconocimiento de la dignidad de la persona como fundamento del orden político y la paz social parecían sugerir que, desde el derecho positivo, se apelaba a realidades de dimensión esencialmente jurídica y preexistentes a la propia formulación normativa.

Positivistas convencidos y cerrados a cualquier realidad jurídica ajena o previa al derecho positivo han mantenido, sin especial perturbación, su posición dogmática, mediante el simple y simplificado argumento de la inexistencia de la cuestión porque cualquier margen para la discusión quedaría neutralizado al arrancar su mismo planteamiento del contenido de una norma de derecho positivo. $\mathrm{Y}$ una 


\section{La Justicia como valor Constitucional}

cosa es - dicen- que ésta acoja, por mención o remisión, categorías, valores o principios dogmáticamente decantados y otra distinta que ello comporte el reconocimiento de dictados jurídicos sellados en la naturaleza humana.

Juristas más flexibles o contemporizadores, sin abdicar de sus propias posiciones pero atentos a recientes tendencias del pensamiento jurídico (como la representada por Dworkin, en la que asume un cierto iusnaturalismo), han parecido asentarse confortablemente en la complacencia por la formulación de la Constitución española, felizmente conciliadora (en favor, según cada uno, de su posición), al operar sobre lo que siempre parecen viejas heridas cicatrizadas y con frecuencia están en carne viva.

d) No importa tanto, sin embargo, recalar en una eventual controversia, en la que convicciones ideológicas o premisas culturales suelen hallar amplio campo para confirmar o debatir sus propios presupuestos, cuanto resaltar la indispensable mediación del Derecho al servicio de la justicia con rechazo de su libre y coyuntural manipulación.

Como si pudieran no resultar suficientes las exigencias propias del Estado de Derecho, en el que de modo inmediato y primario se manifiesta objetivada la voluntad constituyente, el artículo 1.1 refiere explícitamente los valores superiores al ordenamiento jurídico aunque, sin incorrección gramatical ni conceptual, tal referencia pudo ser omitida o, con distinto giro de redacción, pudo hacerse al propio Estado, al orden político, al sistema de convivencia o a la acción de los poderes públicos.

Pero la opción ejercitada al formular el artículo 1.1 subraya con trazos vigorosos, dignos de encomio, el punto de vista jurídico y juridificador desde el que se aborda el diseño del sistema de convivencia. La realista aceptación del carácter político de la materia sobre la que opera ni cohibió la voluntad constituyente de ahormar ese sistema según criterios jurídicos ni excusó el esfuerzo necesario para juridificar los fenómenos de poder -incluso los que por su crudeza parecen más difícilmente reductibles a proposiciones jurídicas-. Aquella voluntad y este esfuerzo, que lucen con rigor a lo largo de todo el texto constitucional, quedan inicial y felizmente proclamados en el artículo 1.1 al cerrar la identificación del Estado constituido insertando en el ordenamiento jurídico los impulsos hacia la consecución de los valores superiores proclamados y, entre ellos relevantemente, la justicia.

5. En definitiva y a modo de conclusión, parece importante resaltar de nuevo la entidad de la justicia entre los valores superiores del ordenamiento jurídico propugnados por el Estado social y democrático de Derecho constituido. 


\section{Landelino Lavilla Alsina}

1056

Y es que, sea uno u otro el sentido en el que el preámbulo de la Constitución afirma los deseos de la Nación española de establecer la libertad y la seguridad, ninguna duda puede caber sobre el desenvolvimiento final de la voluntad política afirmada, en cuanto se orienta a la consecución de los exigentes requerimientos que, en relación con la libertad y la seguridad, son propios de un orden político con capacidad de articularlas, equilibradamente, en la justicia y en el logro del bien de cuantos integran la Nación.

Por otra parte, la fuerza atractiva de la justicia, como valor en cuya plenitud aquellos deseos se hacen realidad o como valor que acompasa en armonía la libertad y la igualdad, se revela así singularmente fecunda en la voluntad constituyente, al margen del mayor o menor rigor académico con que tal voluntad haya sido expresada. Lo que, desde luego, resulta evidente es la deliberada proscripción de un orden político en el que pueda germinar la injusticia al calor de un desentendimiento de los postulados propios de la libertad y la seguridad (condicionantes de un orden económico y social justo, según el preámbulo) o de la libertad y la igualdad en cuya convergente y adecuada composición (en su realidad y efectividad como atributos personales, según el artículo 9.2) adquiera sentido la justicia verdadera en cuanto valor superior que el Estado social y democrático de Derecho propugna como propio de su ordenamiento jurídico.

Cuanto antecede dista de prestar soporte a una severa crítica a la formulación constitucional; trata simplemente de desentrañar su más profundo sentido, según criterios analíticos que rinden, sin embargo, inmediata pleitesía a la razonable intención política del proceso constituyente y a la justeza del texto constitucional aprobado. La exégesis jurídica enlaza así, de modo natural y coherente, con la significación de la Constitución como fenómeno político — no sólo como normaque expresa la originaria voluntad de convivencia pacífica y estable entre todos los españoles.

En un mundo en continua evolución, en el que debiera ser tarea diaria perfeccionar las fórmulas de convivencia social y política para mejor adecuarlas a los postulados de la justicia, la labor y la dedicación de los juristas, de los hombres y las mujeres de Derecho, en su propósito vocacional y profesional de hacer verdad real, efectiva, esos postulados, cobra una acusada relevancia.

Moldear en el Derecho las relaciones y las instituciones sociales, orientar hacia soluciones justas los conflictos que inevitablemente se producen en la vida social, impulsar el desarrollo del derecho positivo para adecuarlo a la cambiante realidad, arbitrar cauces cada vez más 


\section{La Justicia como valor Constitucional}

efectivos que garanticen el respeto de los derechos y libertades individuales. . . todas estas facetas - y otras muchas - configuran la misión de los juristas y alientan su afán de que el progreso que el hombre experimenta en todos los órdenes de la vida discurra siempre en pos $\mathrm{y}$ al calor de los grandes valores que definen la esencia del Derecho. Esto es, ateniéndonos al artículo 1 de la Constitución, la libertad, la justicia, la igualdad y el pluralismo erigidos en valores superiores a cuya realización tiende con esforzada conciencia el ordenamiento jurídico.

El Derecho sigue siendo el universo de la libertad y el más eficaz de los instrumentos disponibles en una sociedad moderna para procurar un marco de convivencia distinguido por el estímulo y no por la resignación, por el afán de excelencia y no por el adocenamiento, en donde la igualdad sea - al menos- posible. La sociedad necesita propiciar y creer que sus ciudadanos pueden ser los arquitectos de sus propias vidas, porque en eso radica el compromiso entre la libertad y la igualdad como presupuesto de la justicia. 